\title{
Genomic-based-breeding tools for tropical maize improvement
}

\author{
Thammineni Chakradhar ${ }^{1} \cdot$ Vemuri Hindu $^{2} \cdot$ Palakolanu Sudhakar Reddy $^{3}$
}

Received: 23 February 2017 / Accepted: 14 August 2017 / Published online: 5 September 2017

(c) Springer International Publishing AG 2017

\begin{abstract}
Maize has traditionally been the main staple diet in the Southern Asia and Sub-Saharan Africa and widely grown by millions of resource poor small scale farmers. Approximately, 35.4 million hectares are sown to tropical maize, constituting around 59\% of the developing worlds. Tropical maize encounters tremendous challenges besides poor agro-climatic situations with average yields recorded $<3$ tones/hectare that is far less than the average of developed countries. On the contrary to poor yields, the demand for maize as food, feed, and fuel is continuously increasing in these regions. Heterosis breeding introduced in early $90 \mathrm{~s}$ improved maize yields significantly, but genetic gains is still a mirage, particularly for crop growing under marginal environments. Application of molecular markers has accelerated the pace of maize breeding to some extent. The availability of array of sequencing and genotyping technologies offers unrivalled service to improve precision in maize-breeding programs through modern approaches such as genomic selection, genome-wide association studies, bulk segregant analysis-based sequencing approaches, etc. Superior alleles underlying complex traits can easily be identified and introgressed efficiently using these sequence-based approaches. Integration of genomic tools and techniques with advanced genetic resources such as nested association
\end{abstract}

Thammineni Chakradhar

drthammineni@gmail.com

1 Sehgal Foundation, C/o International Crops Research Institute for the Semi-Arid Tropics (ICRISAT), Patancheru, Hyderabad 502 324, Telangana, India

2 Department of Biotechnology, Sri Padmavati Mahila Visvavidyalayam, Tirupati, Andhra Pradesh, India

3 International Crops Research Institute for the Semi-Arid Tropics (ICRISAT), Patancheru, Hyderabad 502 324, Telangana, India mapping and backcross nested association mapping could certainly address the genetic issues in maize improvement programs in developing countries. Huge diversity in tropical maize and its inherent capacity for doubled haploid technology offers advantage to apply the next generation genomic tools for accelerating production in marginal environments of tropical and subtropical world. Precision in phenotyping is the key for success of any molecular-breeding approach. This article reviews genomic technologies and their application to improve agronomic traits in tropical maize breeding has been reviewed in detail.

Keywords Maize $\cdot$ Next generation sequencing (NGS) . Genome-wide association studies (GWAS) · Genomic selection (GS) · QTL-seq · Phenotyping · Informatics tools

\section{Introduction}

Maize (Zea mays L.) is a versatile $\mathrm{C}_{4}$ crop grown over a range of agro climatic zones and considered as queen of cereals with high production levels under a variety of environmental conditions. Importantly, maize is the major source of nutritional security among resource poor communities of tropical and sub-tropical regions. The steady growth in income and livelihood of Asia's population has shifted their food preference to high protein foods such as meat and eggs which is translating into increased demand of maize for feed and expected to double by 2050 in Africa and Asia (Babu et al. 2014). To cope with this future demand, farmers in the tropics have to boost maize production and productivity. However, an array of factors such as unpredicted rainfall due to climate change and different types of biotic and abiotic stresses severely constrained maize production and productivity in tropics. 
The total area under maize cultivation in tropical countries is 100 million hectares with $73 \%$ share of worlds maize growing area that accounts for an average yield of 2 tones/hectare (t/ha) against $9 \mathrm{t} / \mathrm{ha}$ in temperate zones (Prasanna et al. 2014). Several African countries are still below $1 \mathrm{t} / \mathrm{ha}$ of average maize yields (Prasanna 2012a, b). The total area under maize cultivation in different tropical geographies verses production over years is shown in Fig. 1. The huge differences in yield of tropical maize could be attributed to recurrent drought in sub-Saharan Africa, excess rain fall and flooding in South and Southeast Asia compounded with evolving pathogens and insect pests due to global climate changes (Cairns et al. 2012). Water logging and drought are major abiotic stress constraints that cause significant crop damage particularly in South and Southeast Asia, where $80 \%$ maize cultivation is still rainfed (IFAD 2002; Osman et al. 2013). Apart from this, tropical maize land races harbour rare and important alleles of biotic stress resistance that are not yet fully discovered (Dao et al. 2014; Sood et al. 2014). To benefit these resources, breeders must be able to extract unique favourable alleles and transfer them into cultivated back grounds. Nevertheless, scientists are trying to address issues through classical-breeding approaches, but time constraints especially the quantitative nature of most of the yield effecting traits and local adaptation problems turned to be serious challenges. The advancements in crop genetics and genomics offer genotyping technologies such as high-throughput sequencing includes the next generation sequencing (NGS) that has improved understanding of genome-wide distribution of allele effects across the wide genetic variation (Perz-de-Castro et al. 2012; Wallace et al. 2014; Thomson 2014). The modern genomic approaches that are discussed in the present review include molecular genetic diversity, genome-wide association studies
(GWAS), genomic selection (GS), joint multiple population analysis, and other relevant techniques.

The invention of sequence-based genomic technologies together with modern genetic resources has revolutionized maize breeding in the recent past. The developed technologies offer new breeding tools to improve genetic gains and hope to rapidly deliver stress resistant and nutritionally superior breeding material in developing countries particularly in Sub-Saharan Africa (SSA) and South Asia regions. In this context, the present review is discussed on the recent progress in genomics of tropical maize breeding in the light of modern technologies and their potential significance. We have attempted to synthesise the genomic research in tropical maize and discussed their implications in marker-assistedbreeding (MAB) programs. We have also discussed the challenges in modern genomics that may form substrate for research and development in tropical maize improvement.

\section{Shift from classical to modern breeding}

Maize has the longest history of breeding for yield and other agronomic traits under stress environments through the traditional breeding methods (Duvick 1977; Duvick et al. 2004). Hybrid breeding, particularly the knowledge and experience of double cross hybrids introduced in the early 1960 s, has been widely adopted to improve tropical maize production and productivity (Fraley 2009). Two major technologies of the 20th century that have made positive impact on maize productivity and breeding efficiency are molecular breeding and doubled haploid (DH) technologies. The continuous challenges that maize crop is undergoing due to dynamic global climate changes and the thirst of science has led to the development of an interdisciplinary science called molecular plant breeding that is revolutionizing crop improvement in the $21 \mathrm{st}$
Fig. 1 Area of cultivation verses production in maize under various tropical ecologies. Mha Metric Hectare, $M t$ Metric ton, $S A$ South Asia, $L A$ Latin America, SSA Sub-Saharan Africa

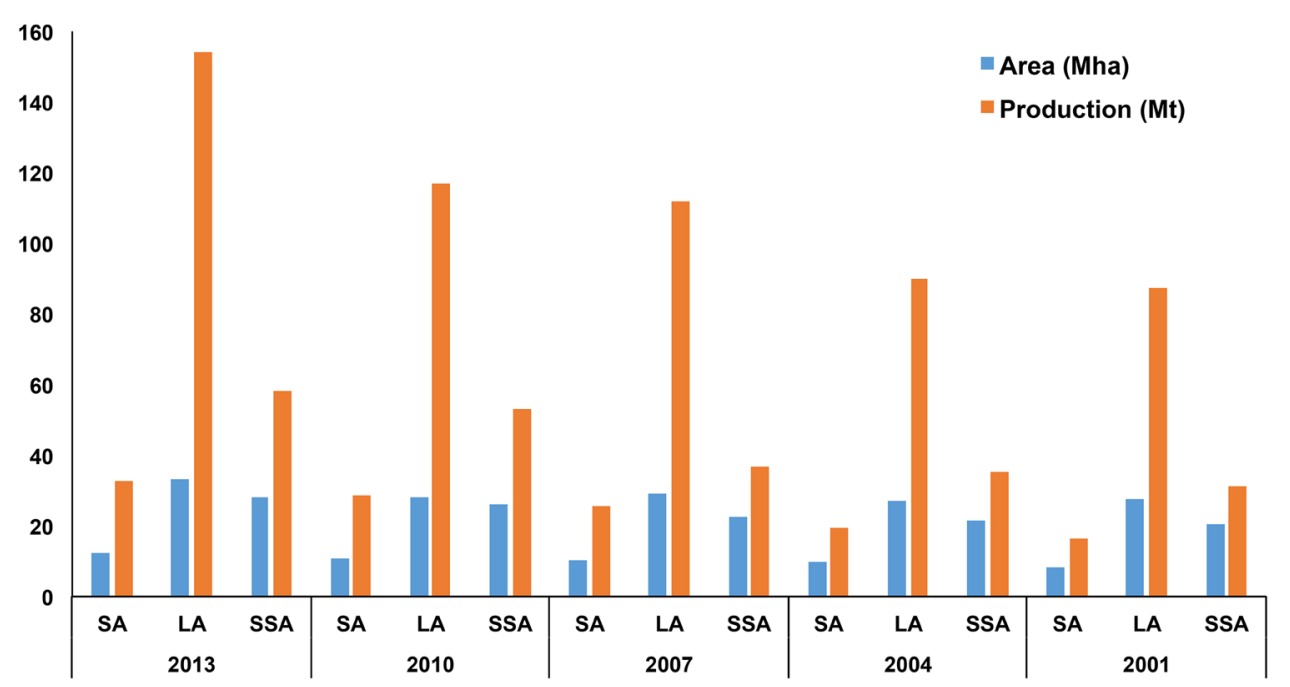


century. This integrates the conventional plant breeding with advances in biotechnology and genomic research through marker-assisted breeding that has direct impact on maize improvement in Asia and Africa (Prasanna et al. 2010; Semagn et al. 2014). Simple sequence repeats (SSR)-based genetic marker technology developed in the last 2 decades has metamorphosed tropical maize research in better understanding of heterotic pattern, trait association studies, recurrent, and back ground selection through marker-assisted back cross breeding (MABB) and also in early selection of complex traits (Prasanna and Hoisington 2003; Benchimol et al. 2005; Shehata et al. 2009). Earlier studies using SSR markers by Sibov et al. (2003) at International Maize and Wheat Improvement Center (CIMMYT) revealed less genetic purity and high heterozygosity in inbreds derived from tropical germplasm. SSR markers for many complex traits such as drought have been developed in maize, validated, and successfully deployed to practical breeding programs. In a product line development program, low-phytate locus (Ipa2) has been successfully transferred into an elite tropical inbred UMI 395 through MABB using a co-dominant SSR (umc2230) marker (Tamilkumar et al. 2014). The second generation genomic technologies discovered after 2000 has shifted crop genomic research from marker-assisted breeding to marker-based breeding. Translation of genomics results of maize into product line development has begun during this period. The maize HapMaps developed through international collaborations using diverse inbred lines have discovered millions of single nucleotide polymorphism
(SNPs) that can be used to advance mapping power and also to identify rare alleles that help in marker trait associations (Chia et al. 2012; Gore et al. 2009).

Parallel to the developments of NGS technologies, research in genetics has discovered novel genetic resources that can utilise the benefits of genomics to gain the maximum genetic gains. Multi-parental crossing designs developed in maize combines the alleles across the locations and also increases the diversity and resolution of quantitative trait loci (QTL) mapping studies (Giraud et al. 2014). One such population developed in maize is Nested Association Mapping (NAM) population by crossing 25 diverse inbred lines with common parent (McMullen et al. 2009) that combines the advantages of both linkage mapping and association mapping. Possible role of various genomic approaches utilising these improved genetic resources in accelerating tropical maize breeding has been discussed below. An overview of the NGS-derived-breeding strategies and genetic resources in enhancing maize genetic gains is depicted in Fig. 2.

\section{Sequencing chemistries and genotyping technologies}

The recent revolutions in sequencing and genotyping technologies offer exciting tools that help in increasing the genetic gains of tropical maize. Since the reference genome sequences (Schnable et al. 2009; Vielle-calzada et al. 2009) are available from public database (maizesequence.org and
Fig. 2 Schematic representation of genomic-assisted breeding for tropical maize improvement. Sequence-based genomic tools when clubbed with genetic resources and phonemic pipelines play an important role in genome-wide genetic marker discovery which in turn are very useful in designing strategies that improve genetic gain in tropical maize. $N A M$ nested association mapping, BCNAM back cross nested association mapping, RILS recombinant inbred lines, NILS near-isogenic lines, $G B S$ genotype by sequencing, $R A D$ seq restriction site-associated DNA sequencing, DDRAD seq double digest RAD sequencing, WGRS whole genome resequencing, GWAS genome-wide association study

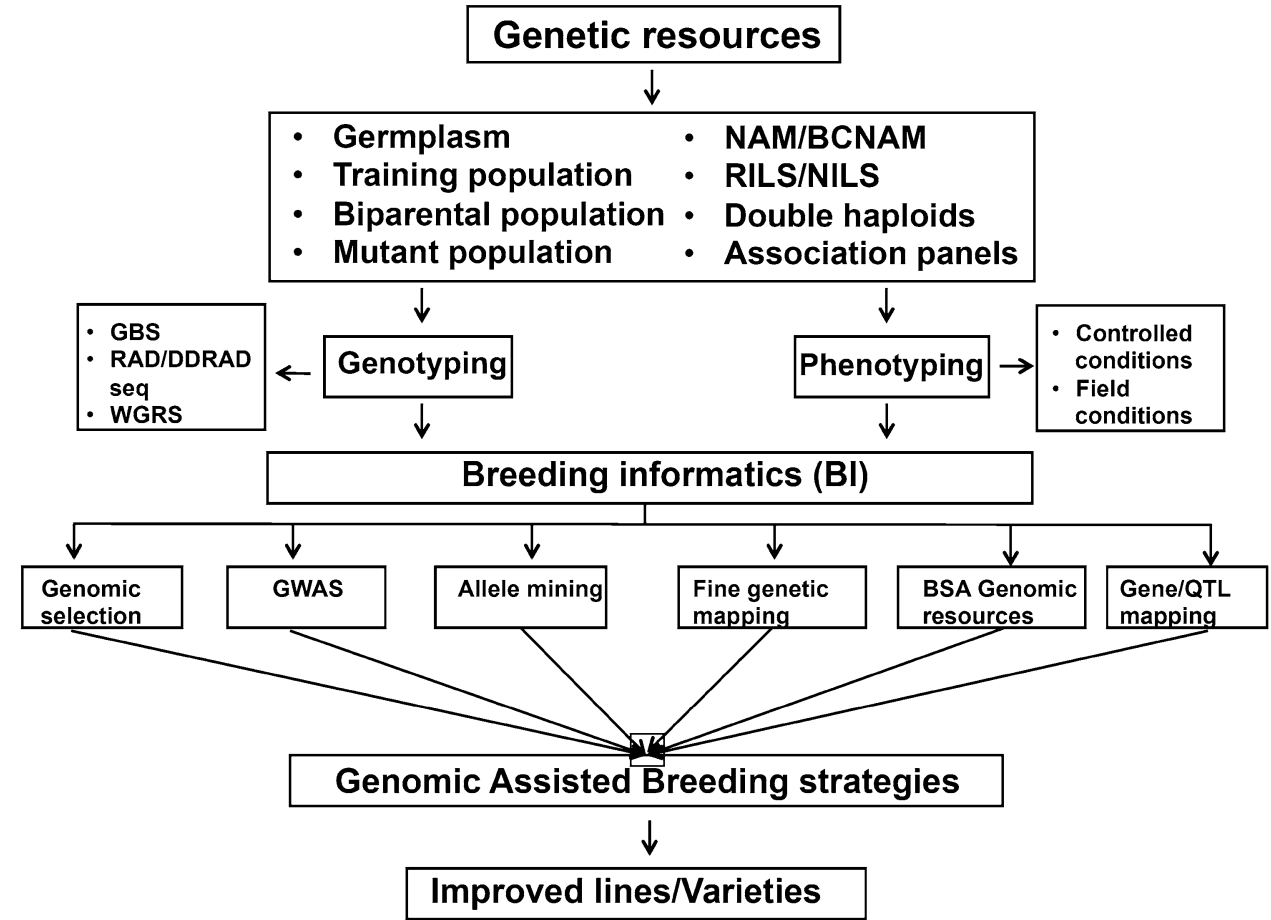


maize GDB), the whole genome resequencing approaches of important lines or bulk segregant analysis (BSA) help in extensive discovery of SNP pools for different heterotic groups and also help to identify rare alleles of agronomic importance. However, most of genomic applications including GWAS and GS would require reduced representation sequence data that generates ample number of SNPs which serves the purpose. Genotyping by Sequencing (GBS) is one such low cost "skim" sequencing technology widely adopted in crop improvement particularly in maize owing to its versatility of multiplexing the samples, imputation of missing data and low cost (Yang et al. 2010; Elshire et al. 2011; Wen et al. 2012). Improved versions, i.e., double digest Restriction site-Associated DNA sequencing (ddRAD) of GBS using different restriction enzymes, could be the choice of interest for applications that may require deep coverage (Paterson et al. 2012). Targeted Amplicon Sequencing (TAS) or targeted enriched sequencing (TER) is another powerful method for detecting rare alleles/SNPs and helps in fine mapping of recombination break points that furtherance trait introgression breeding (Bybee et al. 2011). Using targeted amplicon sequencing, a major QTL for Aluminium ('Al') tolerance was fine mapped on chr10 in tropical maize line and maker identified based on this QTL has been employed in selection of the allele in transgenic lines (Ducrocq et al. 2009). The final goal of any NGS-based project is to identify polymorphism (SNPs) with significant role to identify phenotype. Designing high-throughput breeder friendly marker assays to detect such SNPs is essential to reach benefits of NGS technologies to farmers. Recent development of high-throughput sequencing technologies collectively known as NGS technologies becomes the main pillar for genomic-assisted breeding. Besides, few automated, high capacity PCR-based technologies that are in practice in maize research are discussed. Kompetetive Allele Specific PCR (KASPar) is an endpoint, fluorescent, cost-effective assay that detects SNP and Indel in more flexible manner (http://www.lgcgenomics.com). KASPar assays are available in 96,384 , and 1536 well plate formats that make processing of multiple samples feasible. Many significant SNPs were successfully converted into KASPar assays and have been implemented in routine at CIMMYT maize-breeding programs (Semagn et al. 2014; Kassa et al. 2015). Douglus scientific has proposed an improved and efficient method of KASP, namely, Array Tape Platform and successfully demonstrated in field corn (http://www.douglasscientific.com).

\section{Role of genomics in tropical maize improvement}

Marker-assisted breeding (MAB) based on the traditional linkage mapping is becoming faint owing to the limitations in finding additive or minor QTLs of major effect.
NGS-based methodologies have solved the above problem and are effectively used in maize breeding to enhance genetic gains. As species of tropical origin, huge genomic diversity with rare alleles is present in tropical germplasm. To exploit these superior traits, scientists are focusing on temperate introgressed tropicalized maize as possible source of variation and to overcome biotic stress. However, most of the genomics data and information tools were generated based on temperate germplasm. As maize is a species that has huge genetic diversity between the sister lines, genomic data generated based on temperate genetic architecture of maize may not be applicable for tropical material.

\section{Genetic diversity and allele mining}

Maize is versatile crop with complex genome structure having $80 \%$ repetitive and $32 \%$ paralogous sequences with numerous transposons (Blanc and Wolfe 2004). It is predicted that the extent of nucleotide diversity between any two maize lines is higher than the genetic distance between a chimpanzee and human (Buckler and Stevens 2005). Probably, this led to adaptation of maize to various ecological conditions and environments across the globe. Understanding such huge diversity measured by genomic methodologies is most essential for systematic arrangement of germplasm to heterotic grouping that leads for development of potential hybrids. Correlating molecular genetic diversity and heterosis (hybrid performance) will help to understand general combining ability. It is described that tropical germplasm exhibits higher genetic diversity as compared to temperate germplasm, with respect to stiff and non-stiff stalk synthetics (Hainey et al. 2015). However, comparatively less work was done on genetic diversity of tropical germplasm. Previous genetic diversity studies of maize were predominantly based on SSRs or sequence-tagged microsatellite markers (STMS) (Dubreuil et al. 2006; Sharma et al. 2010; Warburton et al. 2002). Because of their low throughput nature, less probability to detect variation among closely related material, and poor repeatability, usage of SSR-based markers has been ruled out. However, the ease of conducting experiment and co-dominant nature has made them valuable tool for quite long period. This is well supported by genetic variability study among diverse tropical sweet corn inbred lines using microsatellite markers (Kashiani et al. 2012) and molecular diversity studies among 48 land races of tropical origin (Wasala and Prasanna 2012a, b). In both the experiments, the observed polymorphic information content (PIC) was 0.60 .

High-density SNP markers developed through chip-based fixed array platforms (affymetrix, MaizeSNP 50K) or methods such as GBS helps in understanding the diversity of given material at individual loci. This helps in construction of phylogenic trees with high resolution and better 
visualisation of the heterotic groups. Such high-resolution genetic diversity maps help to predict heterosis through analysis of correlation between genetic distance and hybrid performance (Guo and Cooper 2015; Prasanna 2012a, b; Yan et al. 2010b). Diversity patterns in 375 global maize accessions using 50K Illumina array chip revealed key genomic regions responsible for tropical adaptation that can be exploited for favourable QTLs (Bouchet et al. 2013). Heterotic pattern was revealed in core set of 96 African accessions using sequence-based technology (Richard et al. 2016). Unterseer et al. 2014 have developed 600 k SNP chip-Affymetrix Axion Maize Genotyping array that is found more useful in diversity studies of temperate lines than tropical material. Re-sequencing of wild and early domestication varieties helps to identify genomic regions that have undergone selection pressure and harbour useful alleles for stress tolerance.

Identifying the functional polymorphism of alleles within core subsets of original germplasm through allele mining is crucial to improve agronomically important traits. Largescale resequencing works in maize will help to identify specific haplotypes that relates to allelic diversity of useful traits as explained by Xu et al. (2009). Identifying the naturally occurring allelic variations that are functionally different from wild type and those that influence the target traits is really challenging. In silico methods to identify such relations between the SNPs and traits need to be improved. Large-scale genotyping of broad set of DH lines derived from various land races of tropics would give deep insight into the molecular diversity of landraces that would allow mining of new alleles when combined with precise phenotyping. Furthermore, diversity study of individual genes throw light on domestication of early germplasm. Two main approaches exist for allele mining: (1) ecotype target induced local lesions in genomes (Eco-TILLING) and (2) sequencebased methods. Utilising sequence-based approach, allelic diversity in $\beta$-carotene gene in diverse tropical yellow maize lines was dissected along with functional validation. This allelic variation formed basis for maize-breeding program to improve carotenoid levels (Azmach et al. 2013). Genomewide comparative analysis of defensin gene in Turkish maize varieties indicates $334 \mathrm{bp}$ conserved region corresponding to active functional domain that explains adoptive role in embryo germination (Tombuloglu et al. 2015). In general, resequencing is the preferred approach in maize as compared to TILLING strategy to identify minor allelic variations within the groups (Sood et al. 2014).

\section{Genome-wide association studies}

Two of the most popular approaches for dissecting the genetic architecture of complex traits are linkage analysis and association study. Linkage analysis is the traditional method used to sketchily detect the co-segregation of a small genomic region (QTL) governing a trait of interest in families or pedigrees of known ancestry using RFLPs and SSRs. Using linkage mapping, hundreds of marker-trait associations were proved in tropical maize research (Sabadin et al. 2008; Ajmore-Marson et al. 2001; Semagn et al. 2010), but very few could be successfully transferred to commercial breeding programs. The reason could be that the QTLs detected in bi-parental population using interval mapping are relevant only for those breeding programs, which involve parents to detect the QTL. Low heritability and high interference of genotype-by-environment (GxE) are other potential demerits of linkage-based bi-parental mapping studies which restrict fine mapping of traits. On the contrary, association study is a precision and high-resolution method for mapping the casual genes (or loci) underlying complex traits based on Linkage Disequilibrium (LD) in population(s).

Association study broadly falls into two classes: 'candidate-gene studies' and 'whole genome studies'. The 'candidate-gene'-based association study is hypothesisbased analysis. The 'candidate genes' are selected for association mapping, either by their location in a genomic region that has been roughly identified via linkage analysis. Alternatively, whole-genome association study, also called genome-wide association study (GWAS), is an approach for establishing marker-trait associations and most important of this include use of natural genetic resources, i.e., germplasm lines instead of segregating mapping population that saves time and occurrence of historical recombinations (selections) that allows multiple alleles per locus, making increased map resolution. GWAS is a powerful NGS tool, used to dissect complex traits that have been considered as the 'unpolished diamonds' for geneticists.

GWAS is increasingly becoming standard tool for rapidly uncovering marker-trait associations in crops such as maize, where generation of high density markers is feasible and affordable. The popular software used for GWAS is described in Table 1. Numerous statistical methods have been employed, to correct population structure and to minimize spurious associations and this is well discussed by Gupta et al. (2014). In an experiment, Yang et al. (2014) have proposed novel statistical approach called A-D (Anderson-Darling) test that has more power to detect rare alleles which normally could not be identified applying linear models such as general linear model (GLM) and mixed linear model (MLM). The current mixed models perform single locus test associations that ignore population-based bias, which may lead to wrong trait associations. To better explain GWAS in quantitative traits, Segura et al. (2012) have proposed multi-locus mixed models (MLMM) to reduce statistical confoundings in structured populations. The popularity of the mixed-model approach has made it an almost routine GWAS tool in plant studies in the era of big 
Table 1 Important software packages available for GWAS studies

\begin{tabular}{|c|c|c|}
\hline Software & Features & References \\
\hline MERLIN & $\begin{array}{l}\text { Parametric and non-parametric linkage analysis, association } \\
\text { analysis for quantitative traits, ibd and kinship estimation, } \\
\text { haplotyping, error detection, and simulation }\end{array}$ & http://csg.sph.umich.edu/abecasis/merlin/download/ \\
\hline EIGENSOFT & $\begin{array}{l}\text { Detects and corrects for population stratification in genome- } \\
\text { wide association studies using principal components } \\
\text { analysis }\end{array}$ & http://genetics.med.harvard.edu/reich/Reich_Lab/Software.html \\
\hline SNAP & $\begin{array}{l}\text { Web server for finding and annotating proxy SNPs based on } \\
\text { linkage disequilibrium, genomic location, and coverage by } \\
\text { commercial genotyping arrays }\end{array}$ & http://www.broadinstitute.org/mpg/snap/ \\
\hline SHEsis & $\begin{array}{l}\text { A powerful web-based platform for analyses of linkage dis- } \\
\text { equilibrium, haplotype construction, and genetic association } \\
\text { at polymorphism loci }\end{array}$ & http://analysis.bio-x.cn/SHEsisMain.htm \\
\hline PLINK & $\begin{array}{l}\text { Free, open-source whole genome association analysis toolset, } \\
\text { designed to perform a range of basic, large-scale analyses in } \\
\text { a computationally efficient manner }\end{array}$ & http://pngu.mgh.harvard.edu/ purcell/plink/ \\
\hline QTDT & $\begin{array}{l}\text { Interface to perform family-based analyses for quantitative } \\
\text { and discrete traits }\end{array}$ & http://csg.sph.umich.edu//abecasis/QTDT/ \\
\hline UNPHASED & $\begin{array}{l}\text { Versatile application for performing genetic association } \\
\text { analysis }\end{array}$ & https://sites.google.com/site/fdudbridge/software/unphased-3-1 \\
\hline THESIAS & Testing Haplotype Effects In Association Studies & http://ecgene.net/genecanvas/downloads.php?cat_id=1 \\
\hline STRAT & $\begin{array}{l}\text { This is a structured association method, for use in association } \\
\text { mapping, enabling valid case-control studies even in the } \\
\text { presence of population structure }\end{array}$ & http://pritch.bsd.uchicago.edu/software/STRAT.html \\
\hline SNPP & $\begin{array}{l}\text { A dynamic general database management system to manage } \\
\text { high-throughput SNP genotyping data. It provides several } \\
\text { functions, including data importing with comparison, Men- } \\
\text { delian inheritance check within pedigrees, data compiling } \\
\text { and exporting. Furthermore, SNPP may generate files for } \\
\text { repeat genotyping and transform them into files that can be } \\
\text { executed by a liquid handling system }\end{array}$ & http://orclinux.creighton.edu/snpp/ \\
\hline GHOST & $\begin{array}{l}\text { GHOST is a software package for family-based genome wide } \\
\text { association (GWA) analysis, with the ability to infer missing } \\
\text { genotypes using the Elston-Stewart algorithm }\end{array}$ & http://www.sph.umich.edu/csg/chen/ghost/ \\
\hline Gwas central & $\begin{array}{l}\text { A central database of summary-level genetic association } \\
\text { findings }\end{array}$ & http://www.gwascentral.org/ \\
\hline SPAGeDi & $\begin{array}{l}\text { Characterize the spatial genetic structure of mapped individu- } \\
\text { als }\end{array}$ & http://ebe.ulb.ac.be/ebe/SPAGeDi.html \\
\hline mStruct & $\begin{array}{l}\text { Detection of population structure from multi-locus genotype } \\
\text { data }\end{array}$ & http://www.Xray.cz/mstruct/ \\
\hline BAPS 5.0 & Bayesian Analysis of Population Structure & http://www.helsinki.fi/bsg/software/BAPS/ \\
\hline SVS & $\begin{array}{l}\text { Powerful Genotype Association Testing and Statistics, Link- } \\
\text { age Disequilibrium and Haplotype Analysis, Regression } \\
\text { Analysis, Mixed Linear Model Analysis }\end{array}$ & http://www.goldenhelix.com/SNP_Variation/ \\
\hline TASSEL & $\begin{array}{l}\text { Software package to evaluate traits associations, evolutionary } \\
\text { patterns, and linkage disequilibrium }\end{array}$ & http://www.maizegenetics.net/\#!tassel/c17q9 \\
\hline GAPIT & $\begin{array}{l}\text { R package that performs Genome Wide Association Study } \\
\text { (GWAS) and genome prediction }\end{array}$ & http://www.maizegenetics.net/\#!gapit/cmkv \\
\hline JMP Genomics & Calculates population structure and marker-based kinship & http://www.jmp.com/software/genomics/ \\
\hline KING & $\begin{array}{l}\text { Makes use of high-throughput SNP data typically seen in a } \\
\text { genome-wide association study (GWAS) }\end{array}$ & http://people.virginia.edu/ wc9c/KING/ \\
\hline
\end{tabular}

data. MLMM has been successfully used in maize data set to correct population structure and to identify loci associated with provitamin A levels (Owens et al. 2014). Van Inghelandt et al. (2012) have successfully dissected polygenic traits such as flowering time (FT) and northern corn leaf blight (NCLB) resistance using population-based association mapping study and identified significant SNPs using single marker analysis. He also discussed the optimum number of 
SNPs required to explain significant phenotypic variance in different heterotic pools based on the LD decay. Vinayan et al. (2013) identified candidate genomic regions for fodder quality in test cross progenies of tropical origin using data sets of both GBS and 55K infinium chip, rendering GBS as the preferred technology to explain phenotypic variance of complex traits. In another example using subtropical maize lines, Tirunavukkarasu et al. (2014) have identified 61 significant SNPs associated with various traits related to drought using Maize SNP50 bead chip (Illumina, USA) developed by Nepolean et al. (2013) in a panel of 250 elite sub-tropical maize inbreds. They also proved that abscisic acid (ABA)-dependent signalling pathway plays major role in abiotic stress tolerance such as drought. Zaidi et al. (2015) identified consensus genomic regions associated with waterlogging in two independent association panels consisting of tropical germplasm (DTMA and CAAM) following GWAS approach. Root traits are considered to play crucial role in drought stress mitigation in crop plants. Zaidi et al. (2016) have identified 18 SNPs that are significantly associated with more than one trait related to root structure and function in Asia association mapping (CAAM) panel, comprising of 396 diverse tropical maize germplasm. Additional 375 SNPs were discovered for grain yield and shoot biomass under drought stress. Recently, Nair et al. (2015) fine-mapped major QTL for maize streak virus (Msv1) in an association panel consisting of tropical and sub-tropical material using GWAS and found specific haplotypes which are then converted into high throughput marker assays to use in routine breeding programs. This study is a typical example for Genomics-Based-Breeding (GBB) strategy. In another interesting study, 45 SNPs and 15 haplotypes closely associated with Fusarium ear rot (FER) disease resistance were discovered in a set of 818 tropical maize inbred lines using $50 \mathrm{~K}$ maizebead chip method performed in Illumina Infinium SNP genotyping platform (Chen et al. 2016). The GWAS results were validated through linkage mapping study in four bi-parental populations and identified four QTLs linked with disease resistance along with other agronomic traits. This study stood as best example, where the complementary strengths of both linkage and association mapping exploited for trait improvement. In spite of its advantage over linkage-based analysis in discovering marker-trait associations, association mapping (GWAS) has certain limitations such as population structure, less chance to identify rare genetic variants. Use of family-based association or Joint Linkage Association Mapping has been recently proposed that could solve these problems to some extent.

\section{QTL seq}

QTLseq is a novel outcome of modern plant genomics, where in QTLs of complex, traits can easily be detected using whole genome re-sequencing approach bypassing the traditional LD-based detection methods. The phenotypic variation caused by numerous small-effect alleles are difficult to detect in GWAS. Most of the complex traits such as disease resistance, yield, and abiotic tolerance are governed by small and additive QTLs. Identifying and tagging such genomic regions with marker are a challenge to molecular breeders. The availability of high-throughput, low-cost sequencing technologies gave thought to whole genome resequencing of bulk segregants of extreme phenotype to identify rare alleles associated with complex traits (Abe et al. 2012; Swinnen et al. 2012; Parts et al. 2011). This novel NGS technology called QTL-seq was first used to identify QTL associated with blast resistance in rice (Takagi et al. 2013). This technology is gaining significance and can be best choice to dissect and associate complex traits in maize. The authors are working on identifying TLB resistance in maize using QTL-seq approach.

\section{Genomic selection}

The major success with high-throughput genotyping data is its ability to predict phenotype in large populations that has enormous impact on plant breeding. This method of predicting or estimating genomic values of individual lines based on genotyping data without phenotyping is called genomic selection (GS) which is first proposed in animal breeding (Meuwissen et al. 2001) and first suggested by Bearnardo and $\mathrm{Yu}$ (2007) in plant breeding. For predicting breeding values and to make selections, plant breeders have incorporated pedigree information into linear mixed models more recently (Crossa et al. 2010). However, application of such models is not effective because of non-inclusiveness of Mendelian pattern of segregation. In practice, GS involves data from two kinds of populations. A trained data set obtained by thorough genotyping and phenotyping of a reference population is used to predict the phenotype of testing or prediction population which contains only genotyping data. Various statistical methods (GBLUP, Bayes C, and Bayes $\mathrm{C}-\mathrm{Pi}$ ) are employed to estimate the marker effects of testing or validation set. These data of the prediction model are used to estimate breeding values (GEBVs) for unphenotyped candidates. Unlike marker-assisted selection or association mapping studies, GEBVs are based on cumulative effect of all markers related to both minor and major alleles (Hayes and Goddard 2010). Thus, the estimated GEBV may capture more of the genetic variation for the particular trait/traits under selection.

Designing of training population is crucial for calculating the accuracy of prediction models that further could be affected by many factors, including population structure and composition (Jannik et al. 2010; Lorenz et al. 2011; Crossa et al. 2013). GS is widely adopted in maize breeding 
to predict the best untested lines and selection for un-phenotyped traits and to shorten breeding cycle to minimum period of time. While GS is still at low pace in tropical maize improvement program, studies on temperate maize could predict hybrid performance based on genotyping data of parental lines (Massman et al. 2013; Technow et al. 2014). Zhang et al. (2014) have validated prediction accuracy of several agronomic traits for selection of best untested lines derived from 19 tropical bi-parental maize population using low-density GBS as well as fixed number of SNP markers ( 200). They found that low-density markers outperformed in predicting simple traits such as anthesis date and plant height, whereas more complex traits such as grain yield, drought require more SNPs to determine the prediction accuracy. It is complemented by the results obtained by Crossa et al. (2010), where in good prediction values achieved with 1152 SNP markers for host plant resistance of TLB and GLS. It is also observed that prediction accuracy of some traits is consistently low across target environments (Zhang et al. 2014). In similar study using tropical parental material, Zhang et al. (2015) found that increasing $F_{2}$ population from 30 to 90 made to shift prediction accuracy from 0.40 to 0.58 for grain yield under optimal conditions. They also established that increasing population size of training set and number of markers had a positive impact on prediction accuracy of untested lines. Prediction accuracy or factors affecting accuracy of GEBVs of individual lines largely depend on population structure (Desta and Ortiz 2014). Many prediction models are in practice for GS in maize, targeting maximum genetic gains which are influenced by many factors such as sample size, relatedness, marker density, gene effects, heritability, and genetic architecture. Crossa et al. (2010) adopted an improved version of linear models such as Bayesian LASSO for GS and validated it on tropical maize data set obtained from various environments with effective predictive ability for agronomic traits of importance. In another independent study, Gonzalez-Camacho et al. (2012) did comparative study of various models for prediction accuracy of several trait-environmental combinations and found that nonlinear regression models such as reproducing kernel Hilbert spaces (RKHS) and radial basis function neural networks (RBNN) are best suitable ones over Bayesian LASSO model for GS in maize. However, Zhang et al. (2014) used an extension of the genomic best linear unbiased predictor (GBLUP) that can incorporate $G \times E$ interactions to calculate GEBVs for different quantitative traits. Many breeding experiments based on GS are in progress at CIMMYT global breeding programs targeted for tropical world. Mendes and de Souza (2016) have successfully applied GS to predict progenies derived from 250 single crosses of tropical maize, evaluated in 13 environments. Comparison of GS with phenotypic selection in this experiment revealed that prediction accuracies are significantly higher with multi-location data than single location data. These results emphasise the need of evaluating the training set at multiple locations.

GS is extensively used by multinational seed companies in their breeding programs to select inbred lines for various agronomically important traits and even to predict heterosis. Applying GS, drought tolerant maize hybrids (AQUAmax ${ }^{\circledR}$ ) with improved genetic gains were released in US corn belt by Dupont Pioneer (Cooper et al. 2014). Field evaluations revealed that all AQUAmax hybrids performing better than other competitors under water limited conditions without yield penalty (Gaffney et al. 2015). Using GS, pre-breeding material harbouring polygenic favourable alleles generated from $4000+$ land races of tropical origin (Gorjanc et al. 2016).

\section{Phenomics}

Much has been discussed about the opportunities to use sequence-based markers in plant breeding, but the success of any genomic-assisted-breeding program, particularly those targeting stress environments such as drought, depends largely on the precision of its phenotyping data (Cooper et al. 2014). Hence, plant phenomics plays a crucial role in molecular plant breeding. In maize, there have been several reports of QTLs associated with specific phenotype observed under drought stress in diverse mapping populations (Veldboom and Lee 1996; Ribaut et al. 1996, 1997; Frova et al. 1999; Tuberosa et al. 2002), but their reliance to stability across environments is less due to QTL $\times E$ interaction (Messmer et al. 2009). Many publications have emphasized the importance of precise phenotyping, but there is little or no discussion of how to achieve such phenotyping at the scale necessary to support a breeding program. In the last decade, integration of new phenotyping and genomics technologies has enabled successful evaluation of new breeding approaches intended to accelerate the rate of genetic improvement mainly for drought-tolerant maize hybrids for drought-prone environments. Key phenotyping technologies that have been implemented in advanced organizations/industries include: managed drought environments, experimental designs and spatial analysis using mixed model methodology, sensor technologies to measure soil water status during the crop growth and development cycle that enable characterization and modeling of the soil-plant water balance within experiments, and high-throughput measurement of growth and development traits to enable modeling of genotype performance (Tuberosa 2012; Tuberosa and Salvi 2006; Messina et al. 2011). In addition, advances in reflectance spectroscopy, thermal imaging, and remote-sensing technologies have revolutionized crop phenotyping methods including maize and paved the way for the development of high-throughput phenotyping platforms (HTPP) in many 
agriculture-based profitable and non-profitable organizations such as CSIRO, ICRISAT, and DuPont (Vadez et al. 2015). Using remote sense-based HTPP, parameters related to quality and yield levels were measured in 300 test crosses of maize trials (Weber et al. 2012) that explained $40 \%$ of field variance in grain yield. Recently, the university of Barcelona (Spain) and CIMMYT collaboratively developed an aerial phenotyping platform called "skywalker", fitted with high spectral reflectance and thermal imagery cameras that can record phenomics data of canopy and leaf temperatures, biomass, senescence, and leaf gas exchange parameters of hundreds of fields in single take. The methods to characterize root variability were too slow to be incorporated in the breeding cycle. Therefore, root phenomics is getting increasingly important as major QTLs discovered in root genome showed their impact on grain yield (Atkinson et al. 2015), and hence, measuring root dynamics plays a vital role in establishing marker trait associations and yield predictions. Plant phenomics facility at ICRISAT has developed a lysimetric system to measure water uptake in large scale using 1.2-2 m length with $20 \mathrm{~cm}$ diameter cylinders which can be best used to study root traits in maize. In recent years, demand-driven maize production has expanded maize cultivation into marginal lands which have the potential to generate a greater number of drought-prone maize production environments that can lead to yield instability at local and national levels in near future (Edmeades et al. 1999; IPCC 2007; Hillel and Rosenzweig 2005). Therefore, knowledgebased approach of phenomics for improving maize yield for drought prone condition which has predicted to occur with greater frequency in the future and to develop more focused field screening techniques that increase rate of gain for yield stability under conditions of variable and unpredictable water stress, will be beneficial.

\section{Challenges and future perspective}

\section{Choice of genotyping platform}

The availability of different genotyping methods and continuous evolving technologies in sequencing chemistries has put challenge on molecular breeder as which method is best suitable for their breeding program. Cost of genotyping is the major determining factor for adopting appropriate genotyping technologies in plant breeding. GBS is routinely used sequencing approach for low coverage molecular-breeding applications owing to its versatility of multiplexing the samples, imputation of missing data at low cost (Yang et al. 2010; Elshire et al. 2011; Wen et al. 2012). Missing data and low coverage are two potent shortcomings of GBS limiting its wide adaptability. Chip-based fixed SNP detection methods are considered as alternative genotyping technologies for GBS. Initial SNP chip was developed by Illumina on affymetirx platform with 1536 SNPs from temperate material that has found limited application (Yan et al. 2010a, b). Later improved versions with millions of SNPs were developed, among which Illumina ${ }^{\circledR}$ MaizeSNP50K Bead chip is most popular and used in large number of genotyping studies. MaizeSNP600K chip with increased number of SNPs, with improved fixation index $\left(F_{\mathrm{ST}}\right)$ was developed on Affymetrix ${ }^{\circledR}$ Axiom $^{\circledR}$ platform (Unterseer et al. 2014). Recently, Xu et al. (2017) have developed 55K Maize SNP chip that has equal representation of SNPs derived from tropical germplasm that may be useful for genetic diversity studies, QTL detection studies in tropical maize populations. However, if the purpose is to have deep sequencing data more efficient methods such as RAD/ddRAD could be the choice of approach (Peterson et al. 2012). The depth and coverage are more in these sequencing technologies compared to GBS. On other hand, chip-based fixed array methods such as Fluidigms Dynamic Array, Douglas Scientific Array Tape, and KASP are available for routine trait specific SNP detection in larger populations. Molecular breeders at present have variety of such genotyping methods at their disposal which are collectively known as next-generation sequencing-based genotyping (NGG) technologies. Prior in selecting suitable NGG, knowledge of population structure, linkage disequilibrium (LD) of targeted region, cost, flexibility of technology, number of samples, ease of multiplexing, etc. are to be considered. Kompetitive allele-specific PCR (KASPar) technique has gained popularity for lower cost single plex genotyping in maize (Semagn et al. 2014; Dao et al. 2014). More advanced flexible, high-throughput SNP genotyping systems have come up with much reduced reaction volume than KASPar $(5 \mu \mathrm{L})$ to minimize cost effect that include Array Tape $(800 \mathrm{~nL}-1.6 \mu \mathrm{L})$ introduced by Douglas Scientific and the openArray system (3072 reactions/33 nL @ 70,000 data points) from Life Technologies and Dynamic Arrays from Fluidigm. Apparently, maize has more diffuse genetic architecture compared to other cereal crops, displaying large number of small genes effects with major phenotype (Buckler et al. 2009; Tian et al. 2011; Cook et al. 2012), allelic variation within genes (Yan et al. 2010a; Poland et al. 2011) and segregation distortion (McMullen et al. 2009). Hence, keeping in view of these facts of maize genome, particularly high diversity nature of tropical maize, one can select the right genotyping platform suitable for their application.

\section{Decision support tools}

Continuous update on sequencing technologies, producing quality reads which minimize the errors has shifted the real challenges like how to tackle the flooding sequence data coming from sequencing programs. This requires more 
sophisticated algorithms and software. Since reference genome for maize is available, assembly of generated short reads could not be critical, and hence, focus should be given to improve mapping softwares that run faster. Time is critical in alignment technologies, because one would like to know the quality of data before running next sample. Commonly used mapping tools are Bowtie, BWA, and TopHat. Bowtie is most popular open source tool that works well with sequence $<3 \%$ difference from reference genome. However, Bowtie works better with 'gapped alignment' (Indels) than other tools such as BWA and ELND. These tools provide mapping quality scores for each alignment read. Besides that, SOAP 2 is another promising alignment tool of choice that functions more efficiently (http://soap.genomics.org.cn) for mapping. Recently, Xu et al. (2014) demonstrated that ANNOVAR tools are best for filtering SNPs significantly associated with heritable phenotype. After alignment, SNPs can be detected using SAM tools or GigaBayes. Another major challenge is filling the gaps of missing data obtained in skim seq technologies such as GBS-making missing data more sensible. Imputation is thus critical for effectively using the output of low-coverage and very few bioinformatic tools are available to perform accurate genotype imputation on these cases (Swarts et al. 2014).

\section{Doubled haploid technology}

The second major innovation after identifying 'heterosis' breeding in maize is doubled haploid technology (DH) through in vivo haploid induction that has been largely adopted by commercial breeding programs ( $>80 \%)$ (Masuka et al. 2017). The technology has been heavily apprised for reducing the breeding cycle to generate parental lines there by increasing selection gains (Geiger and Gordillo 2009; Prasanna 2012a, b; Battistelli et al. 2013; Dwivedi et al. 2015). An anthocyanin-based phenotypic marker imparted by dominant allele "R1-nj" is key to identify the resultant haploid kernels from the cross between source germplasm $\left(F_{1} / F_{2}\right)$ and inducer lines. However, few tropical source material showed poor or no expression of this colour phenotype due to presence of dominant anthocyanin inhibitor allele (C1-I) that made difficult in differentiating haploid kernels. Chaikam et al. (2015) have identified molecular marker to screen and validate the source germplasm before making them involved in DH program. DNA extraction from endosperm of haploid kernels (Halilu et al. 2013) allows germination of seed thus improves haploid detection through MAS and saving precious material.

The current induction rate of haploids is less than $10 \%$ in tropical source germplasm, which need to be enhanced (Prigge et al. 2012a, b). The main reason for less success rate of haploid induction could be attributed to adaptability of haploid inducers used in DH program that are of temperate origin. CIMMYT had taken initiative to solve this challenge by developing tropically adapted inducer lines (TAILS) in collaboration with the university of Hohenheim (Prigge et al. 2011). Efforts were being made to further improve haploid induction rate by attempting crosses between TAILS (Khakwani et al. 2015). A major QTL "qhir11" has been identified on chromosome1 (Dong et al. 2013) which could be the potential candidate for introgression into elite backgrounds to further improve the genetic gains of inducer lines. However, usage of single inducer (UH400) and substantial difference of Logarithm of ODDs (LOD) among population limits the application of qhir11 in improving inducer line selection. The recent genomic methodologies may help in identifying the haploid induction regions in the genome of inducer lines. Introgression of these regions into elite backgrounds using marker-assisted selections will improve the success rate of DH. Hu et al. (2016) have applied GWAS in 53 haploid inducer lines and identified a specific haplotype allele common to all inducers. Using resequence data and a novel approach called conditional haplotype extension (CHE), the authors further identified three candidate genes underlying the QTLs that are crucial for haploid induction efficiency. This helps to develop tropicalized inducer lines with maximum genetic gain. In a recent study, proof of concept has been established on developing haploid inducer lines in maize using centromere-mediated genome elimination method (Kelliler et al. 2016). An extensive discussion about this technology and its application in plant breeding has been reviewed recently (Britt and Kuppu 2016).

\section{Way forward}

Application of genomic tools for maize improvement has increased tremendously in recent years. Utilising these opportunities, significant development in enhancing genetic gains has happened in temperate maize through systematic understanding of the genetic diversity of germplasm, identification of candidate genomic regions by high resolution maps, and also identification of recombination break points that help in better introgression of useful alleles. Prediction of untested lines for better and shortening breeding cycle could also be possible with advancements in NGS technologies and informatics. It is high time to translate these discoveries into tangible products to accelerate tropical maizebreeding programs. There has been a gap, however, between the discovery of useful genes and QTLs and their deployment in breeding programs. Only few demonstrated examples of marker-assisted selection (MAS) products exist in the farmers' fields of developing world, having a significant impact (Ho et al. 2002; Babu et al. 2005). 'Vivek QPM9' is the first MAS product with improved quality protein, recommended for farmer adoption in India (Gupta et al. 2009). 
However, this is about to change, with the availability of high-throughput genotyping and sequencing technologies, the field of molecular breeding is now poised towards product line development for accelerating the crop improvement in maize. However, improved cultivars with improved genetic gains alone may not change the livelihood of several million smallholder farmers worldwide. It should be complemented with sustainable crop and natural resource management practices, effective policies for successful implementation of research technologies and market strategies.

Acknowledgements The authors wish to thank Dr. Suri M. Sehgal, founder of SM Sehgal foundation for his continuous support and encouragement for corn improvement in developing countries.

\section{References}

Abe A, Kosugi S, Yoshida K, Natsume S, Takagi H, Kanzaki H, Matsumura H, Yoshida K, Mitsuoka C, Tamiru M, Innan H, Cano L, Kamoun S, Terauchi R (2012) Genome sequencing reveals agronomically important loci in rice using MutMap. Nat Biotechnol 30:174-178

Ajmore-Marsan P, Gorni C, Chitto` A, Redaelli R, Van Vijk R, Stam P, Motto M (2001) Identification of QTLs for grain yield and grainrelated traits of maize (Zea mays L.) using an AFLP map, different testers and cofator analysis. Theor Appl Genet 102:230-243

Atkinson JA, Wingen LU, Griffiths M, Pound MP, Gaju O, Foulkes MJ, Le Gouis J, Griffiths S, Bennett MJ, King J, Wells DM (2015) Phenotyping pipeline reveals major seedling root growth QTL in hexaploid wheat. J Exp Bot 66:2283-2292

Azmach G, Gedil M, Menkir A, Spillane C (2013) Marker-trait association analysis of functional gene markers for provitamin A levels across diverse tropical yellow maize inbred lines. BMC Plant Biol 13:227-231

Babu R, Nair SK, Kumar A, Venkatesh S, Sekhar JC, Singh NN, Srinivasan G, Gupta HS (2005) Two-generation marker-aided backcrossing for rapid conversion of normal maize lines to quality protein maize (QPM). Theor Appl Genet 111:888-897

Babu R, Nair SK, Vinayan MT, Zaidi PH, Vivek BS, Prasanna BM (2014) In: Paroda R et al (eds) Proceedings of 12th Asian Maize Conference and Expert Consultation on Maize for Food, Feed, Nutrition and Environmental Security. Bangkok, Thailand, pp 81-84

Battistelli GM, Von Pinho RG, Justus A, Couto EGO, Balestre M (2013) Production and identification of doubled haploids in tropical maize. Genet Mol Res 12:4230-4242

Benchimol LL, de Souza CL, de Souza AP (2005) Microsatellite-assisted backcross selection in maize. Genet Mol Biol 28:789-797

Bernardo R, Yu J (2007) Prospects for genomewide selection for quantitative traits in maize. Crop Sci 47(3):1082-1090

Blanc G, Wolfe KH (2004) Widespread paleopolyploidy in model plant species inferred from age distributions of duplicate genes. Plant Cell 16:1667-1678

Bouchet S, Servin B, Bertin P, Madur D, Combes V, Dumas F, Brunel D, Laborde J, Charcosset A, Nicolas S (2013) Adaptation of maize to temperate climates: mid- density genome-wide association genetics and diversity patterns reveal key genomic regions with a major contribution of the Vgt2 (ZCN8) locus. PLoS One 8:e71377
Britt AB, Kuppu S (2016) Cenh3: an emerging player in haploid induction technology. Front Plant Sci 7:357-368

Buckler ES, Stevens NM (2005) Maize origins, domestication, and selection. In: Motley TJ, Zerega N, Cross H (eds) Darwin's harvest. Columbia University Press, New York, pp 67-90

Buckler ES, Holland JB, Bradbury PJ, Acharya CB, Brown PJ, Browne C, Ersoz E, Flint- Garcia S, Garcia A, Glaubitz JC, Goodman MM, Harjes C, Guill K, Kroon DE, Larsson S, Lepak NK, Li HH, Mitchell SE, Pressoir G, Peiffer JA, Rosas MO, Rocheford TR, Romay MC, Romero S, Salvo S, Villeda HS, da Silva HS, Sun Q, Tian F, Upadyayula N, Ware D, Yates H, Yu JM, Zhang ZW, Kresovich S, McMullen MD (2009) The genetic architecture of maize flowering time. Science 325:714-718

Bybee SM, Bracken-Grissom H, Haynes BD, Hermansen RA, Byers RL, Clement MJ, Udall JA, Wilcox ER, Crandall KA (2011) Targeted amplicon sequencing (TAS): a scalable next-gen approach to multilocus, multitaxa phylogenetics. Genome Biol Evol 3:1312-1323

Cairns JE, Sonder K, Zaidi PH, Verhulst N, Mahuku G, Babu R, Nair SK, Das B, Govaerts B, Vinayan MT, Rashid Z, Noor JJ, Devi P, Vicente FS, Prasanna BM (2012) Maize production in a changing climate: impacts, adaptation, and mitigation strategies. Adv Agron 114:1-58

Chaikam V, Nair SK, Babu R, Martinez L, Tejomurtula J, Boddupalli PM (2015) Analysis of effectiveness of R1-nj anthocyanin marker for in vivo haploid identification in maize and molecular markers for predicting the inhibition of R1-nj expression. Theor Appl Genet 128:159-171

Chen J, Shrestha R, Ding J, Zheng H, Mu C, Wu J, Mahuku G (2016) Genome-wide association study and QTL mapping reveal genomic loci associated with Fusarium ear rot resistance in tropical maize germplasm. G3 Genes Genom Genet 6(12):3803-3815

Chia JM, Song C, Bradbury PJ, Costich D, de Leon N, Doebley J, Elshire RJ, Gaut B, Geller L, Glaubitz JC, Gore M, Guill KE, Holland J, Hufford MB, Lai JS, Li M, Liu X, Lu YL, McCombie R, Nelson R, Poland J, Prasanna BM, Pyhajarvi T, Rong TZ, Sekhon RS, Sun Q, Tenaillon MI, Tian F, Wang J, Xu X, Zhang ZW, Kaeppler SM, Ross- Ibarra J, McMullen MD, Buckler ES, Zhang GY, Xu YB, Ware D (2012) Maize HapMap2 identifies extant variation from a genome in flux. Nat Genet 44:803-807

Cook JP, McMullen MD, Holland JB, Tian F, Bradbury P, Ross-Ibarra J, Buckler ES, Flint- Garcia SA (2012) Genetic architecture of maize kernel composition in the nested association mapping and inbred association panels. Plant Physiol 158:824-834

Cooper M, Gho C, Leafgren R, Tang T, Messina C (2014) Breeding drought-tolerant maize hybrids for the US corn-belt: discovery to product. J Exp Bot 65:6191-6204

Crossa J, de los Campos G, Perez P, Gianola D, Burgueno J, Araus JL, Makumbi D, Singh RP, Dreisigacker S, Yan JB, Arief V, Banziger M, Braun HJ (2010) Prediction of genetic values of quantitative traits in plant breeding using pedigree and molecular markers. Genetics 186:713-724

Crossa J, Beyene Y, Kassa S, Perez P, Hickey JM, Chen C, de los Campos G, Burgueno J, Windhausen VS, Buckler E, Jannink JL, Cruz MAL, Babu R (2013) Genomic prediction in maize breeding populations with genotyping-by-sequencing. G3 Genes Genom Genet 3:1903-1926

Dao A, Sanou J, Mitchell SE, Gracen V, Danquah EY (2014) Genetic diversity among INERA maize inbred lines with single nucleotide polymorphism (SNP) markers and their relationship with CIMMYT, IITA, and temperate lines. BMC Genet 15:127-131

Desta ZA, Ortiz R (2014) Genomic selection: genome-wide prediction in plant improvement. Trends Plant Sci 19:592-601 
Dong X, Xu X, Miao J, Li L, Zhang D, Mi X, Liu C, Tian X, Melchinger AE, Chen S (2013) Fine mapping of qhir1 influencing in vivo haploid induction in maize. Theor Appl Genet 126:1713-1720

Dubreuil P, Warburton M, Chastanet M, Hoisington D, Charcosset A (2006) More on the introduction of temperate maize into Europe: large-scale bulk SSR genotyping and new historical elements. Maydica 51:281-291

Ducrocq S, Giauffret C, Madur D, Combes V, Dumas F, Jouanne S, Coubriche D, Jamin P, Moreau L, Charcosset A (2009) Fine mapping and haplotype structure analysis of a major flowering time quantitative trait locus on maize chromosome 10. Genetics 183:1555-1563

Duvick DN (1977) Genetic rates of gain in hybrid maize yields during the past 40 years. Maydica 22:187-196

Duvick DN, Smith JSC, Cooper M (2004) Long-term selection in a commercial hybrid maize breeding program. In: Janick J (ed) Plant breeding reviews part 2. Wiley, New York, pp 109-151

Dwivedi SL, Britt AB, Tripathi L, Sharma S, Upadhyaya HD, Ortiz R (2015) Haploids: constraints and opportunities in plant breeding. Biotechnol Adv 33:812-829

Edmeades GO, Bolanos J, Chapman SC, Lafitte HR, Banziger M (1999) Selection improves drought tolerance in tropical maize populations: I. Gains in biomass, grain yield, and harvest index. Crop Sci 39:1306-1315

Elshire RJ, Glaubitz JC, Sun Q, Poland JA, Kawamoto K, Buckler ES, Mitchell SE (2011) A robust, simple genotyping-by-sequencing (GBS) approach for high diversity species. PLoS One 6:e19379

Fraley RT (2009) Molecular genetic approaches to maize improvement-an introduction. In: Krizetal (eds) Molecular genetic approaches to maize improvement. Springer, Berlin, pp 3-6

Frova C, Krajewski P, di Fonzo N, Villa M, Sari-Gorla M (1999) Genetic analysis of drought tolerance in maize by molecular markers I. Yield components. Theor Appl Genet 99:280-288

Gaffney J, Schussler J, Löffler C, Cai W, Paszkiewicz S, Messina C, Cooper M (2015) Industry-scale evaluation of maize hybrids selected for increased yield in drought-stress conditions of the US Corn Belt. Crop Sci 55:1608-1618

Geiger HH, Gordillo GA (2009) Doubled haploids in hybrid maize breeding. Maydica 54:485-499

Giraud H, Lehermeier C, Bauer E, Falque M, Segura V, Bauland C, Camisan C, Campo L, Meyer N, Ranc N, Schipprack W, Flament P, Melchinger AE, Menz M, Moreno- Gonzalez J, Ouzunova M, Charcosset A, Schon CC, Moreau L (2014) Linkage disequilibrium with linkage analysis of multiline crosses reveals different multiallelic QTL for hybrid performance in the flint and dent heterotic groups of maize. Genetics 198:1717-1734

Gonza'lez-Camacho JM, de los Campos G, Pe'rez P, Gianola D, Cairns JE, Mahuku G, Babu R, Crossa J (2012) Genome-enabled prediction of genetic values using radial basis function neural networks. Theor Appl Genet 125:759-771

Gore MA, Chia JM, Elshire RJ, Sun Q, Ersoz ES, Hurwitz BL, Peiffer JA, McMullen MD, Grills GS, Ross-Ibarra J, Ware DH, Buckler ES (2009) A first-generation haplotype map of maize. Science 326:1115-1117

Gorjanc G, Jenko J, Hearne SJ, Hickey JM (2016) Initiating maize prebreeding programs using genomic selection to harness polygenic variation from landrace populations. BMC Genom 17(1):30

Guo M, Cooper M (2015) Future maize hybrid development: breeding with assistance of molecular and genomics technologies and transgenics. In: Wusirika R, Bohn M, Lai J, Kole C (eds) Genetics, genomics and breeding of maize. CRC Press, Boca Raton, pp 89-119

Gupta HS, Agrawal PK, Mahajan V, Bisht GS, Kumar A, Verma P, Srivastava A, Saha S, Babu R, Pant MC, Mani VP (2009) Quality protein maize for nutritional security: rapid development of short duration hybrids through molecular marker assisted breeding. Curr Sci India 96:230-237

Gupta PK, Kulwal PL, Jaiswal V (2014) Association mapping in crop plants: opportunities and challenges. In: Friedmann T et al (eds) Advances in genetics 85. Academic Press, Cambridge, pp 109-148

Hainey C, Rafalski JA, Hanafey M, Zhang Y, Krespan W, Tingey S (2015) Genomic distribution of genetic diversity in elite maize germplasm. In: Ramakrishna et al (eds) Genetics, genomics and breeding of maize. CRC, New Yark, pp 51-63

Halilu AD, Ado SG, Usman IS, Appiah-Kubi D (2013) Prospects of endosperm DNA in maize seed characterization. Maydica 58:288-290

Hayes B, Goddard M (2010) Genome-wide association and genomic selection in animal breeding. Genome 53:876-883

Hillel D, Rosenzweig C (2005) The role of biodiversity in agronomy. Adv Agron 88:1-34

Ho J, McCouch S, Smith M (2002) Improvement of hybrid yield by advanced backcross QTL analysis in elite maize. Theor Appl Genet 105:440-448

Hu H, Schrag TA, Peis R, Unterseer S, Schipprack W, Chen S, Lai J, Yan J, Prasanna BM, Chaikam V (2016) The genetic basis of haploid induction in maize identified with a novel genome-wide association method. Genetics 202(4):1267-1276

IFAD (2002) Assesment of Rural Poverty: Asia and the Pacific Asia and the Pacific Division, project management Department. International Fund for Agriculture Development. http://www.ifad.org/ poverty/region/pi/PI_part1.pdf

IPCC (2007) Climate change (2007) In: Solomon et al (eds) Assessment report of the intergovernmental panel on climate change. Cambridge University Press, Cambridge

Jannink JL, Lorenz AJ, Iwata H (2010) Genomic selection in plant breeding: from theory to practice. Brief Funct Genomics 9:166-177

Kashiani P, Saleh G, Panandam JM, Abdullah NAP, Selamat A (2012) Molecular characterization of tropical sweet corn inbred lines using microsatellite markers. Maydica 57:154-163

Kassa S, Beyene Y, Babu R, Nair S, Gowda M, Das B, Tarekegne A, Mugo NS, Mahuku G, Worku M, Warburton LM, Olseu SM, Prasanna BM (2015) QTL mapping and molecular breeding for developing stress resilient maize for sub-Saharan Africa. Crop Sci 5:1-11

Kelliher T, Starr D, Wang W, McCuiston J, Zhong H, Nuccio ML, Martin B (2016) Maternal haploids are preferentially induced by CENH3-tailswap transgenic complementation in maize. Front Plant Sci 7:414

Khakwani K, Dogar MR, Ahsan M, Hussain A, Asif M, Malhi AR, Altaf M (2015) Development of maize haploid inducer lines and doubled haploid lines in Pakistan. Br Biotechnol J 8:1-7

Lorenz AJ, Chao S, Asoro FG, Heffner EL, Hayashi T, Iwata H, Smith KP, Sorrells ME, Jannink JL (2011) Genomic selection in plant breeding: knowledge and prospects. Adv Agron 110:77-123

Marsan PA, Gorni C, Chitto A, Redaelli R, van Vijk R, Stam P, Motto M (2001) Identification of QTLs for grain yield and grain-related traits of maize (Zea mays L.) using an AFLP map, different testers, and cofactor analysis. Theor Appl Genet 102:230-243

Massman JM, Gordillo A, Lorenzana RE, Bernardo R (2013) Genomewide predictions from maize single-cross data. Theor Appl Genet 126:13-22

Masuka B, Atlin GN, Olsen M, Magorokosho C, Labuschagne M, Crossa J, Vivek BS, Macrobert J (2017) Gains in maize genetic improvement in eastern and southern Africa: I. CIMMYT hybrid breeding pipeline. Crop Sci 57:168-179

McMullen MD, Kresovich S, Villeda HS, Bradbury P, Li H, Sun Q, Flint-Garcia S, Thornsberry J, Acharya C, Bottoms C, Brown P, Browne C, Eller E, Guill K, Harjes C, Kroon D, Lepak N, 
Mitchell SE, Peterson B, Pressoir G, Romero S, Rosas MO, Salvo S, Yates H, Hanson M, Jones E, Smith S, Glaubitz JC, Goodman M, Ware D, Holland JB, Buckler ES (2009) Genetic properties of the maize nested association mapping population. Science 325:737-740

Mendes MP, de Souza CL (2016) Genomewide prediction of tropical maize single-crosses. Euphytica 209(3):651-663

Messina CD, Podlich D, Dong Z, Samples M, Cooper M (2011) Yield-trait performance landscapes: from theory to application in breeding maize for drought tolerance. J Exp Bot 62:855-868

Messmer R, Fracheboud Y, Banziger M, Vargas M, Stamp P, Ribaut JM (2009) Drought stress and tropical maize: QTL-by-environment interactions and stability of QTLs across environments for yield components and secondary traits. Theor Appl Genet 119:913-930

Meuwissen THE, Hayes BJ, Goddard ME (2001) Prediction of total genetic value using genome-wide dense marker maps. Genetics 157:1819-1829

Nair SK, Babu R, Magorokosho C, Mahuku G, Semagn K, Beyene Y, Das B, Mukambi D, Kumar PL, Boddupalli PM (2015) Fine mapping of Msv1, a major QTL for resistance to Maize Streak Virus leads to development of production markers for breeding pipelines. Theor Appl Genet 128:1839-1854

Nepolean T, Hossain F, Shiriga K, Mittal S, Arora K, Rathore A, Mohan S, Shah T, Sharma R, Namratha PM, Mithra ASV, Mohaptara T, Gupta HS (2013) Unravelling the genetic architecture of subtropical maize (Zea mays L.) lines and their utility in breeding programs. BMC Genom 14:877-890

Osman KA, Tang B, Wang YP, Chen JH, Yu F, Li L, Han XS, Zhang ZX, Yan JB, Zheng YL, Yue B, Qiu FZ (2013) Dynamic QTL analysis and candidate gene mapping for waterlogging tolerance at maize seedling stage. PLoS One 8:e79305

Owens BF, Lipka AE, Magallanes-Lundback M, Tiede T, Diepenbrock CH, Kandianis CB, Kim E, Cephala J, Buell CR, Buckler ES (2014) A foundation for provitamin A biofortification of maize: genome-wide association and genomic prediction models of carotenoid levels. Genetics 198(4):1699-1716

Parts L, Cubillos FA, Warringer J, Jain K, Salinas F, Bumpstead SJ, Molin M, Zia A, Simpson JT, Quail MA, Moses A, Louis EJ, Durbin R, Liti G (2011) Revealing the genetic structure of a trait by sequencing a population under selection. Genome Res 21:1131-1138

Perez-de-Castro AM, Vilanova S, Canizares J, Pascual L, Blanca JM, Diez MJ, Prohens J, Pico B (2012) Application of genomic tools in plant breeding. Curr Genom 13:179-195

Peterson BK, Weber JN, Kay EH, Fisher HS, Hoekstra HE (2012) Double digest RADseq: an inexpensive method for de novo SNP discovery and genotyping in model and non-model species. PLoS One 7:e37135

Poland JA, Bradbury PJ, Buckler ES, Nelson RJ (2011) Genomewide nested association mapping of quantitative resistance to northern leaf blight in maize. Proc Natl Acad Sci USA 108:6893-6898

Prasanna BM (2012a) Diversity in global maize germplasm: characterization and utilization. J Biosciences 37:843-855

Prasanna BM (2012b) Molecular breeding and biotechnology for maize improvement in the developing world: challenges and opportunities. In: Proceedings of the 3rd National Maize Workshop of Ethiopia, pp 87-93

Prasanna BM, Hoisington DA (2003) Molecular breeding for maize improvement: an overview. Indian J Biotechnol 2:85-98

Prasanna BM, Pixley K, Warburton ML, Xie CX (2010) Molecular marker-assisted breeding options for maize improvement in Asia. Mol Breed 26:339-356

Prasanna B, Babu R, Nair S, Semagn K, Chikam V, Cairns J (2014) Molecular marker-assisted breeding for tropical maize improvement. In: Ramakrishna et al (eds) Genetics, genomics and breeding of maize. CRC, New York, pp 89-119

Prigge V, Sanchez C, Dhillon BS, Schipprack W, Araus JL, Banziger M, Melchinger AE (2011) Doubled haploids in tropical maize: I. Effects of inducers and source germplasm on in vivo haploid induction rates. Crop Sci 51:1498-1506

Prigge V, Schipprack W, Mahuku G, Atlin GN, Melchinger AE (2012a) Development of in vivo haploid inducers for tropical maize breeding programs. Euphytica 185:481-490

Prigge V, Xu XW, Li L, Babu R, Chen SJ, Atlin GN, Melchinger AE (2012b) New insights into the genetics of in vivo induction of maternal haploids, the backbone of doubled haploid technology in maize. Genetics 190:781-793

Ribaut JM, Hoisington DA, Deutsch JA, Jiang C, Gonzalez-de-Leon D (1996) Identification of quantitative trait loci under drought conditions in tropical maize. 1. Flowering parameters and the anthesis-silking interval. Theor Appl Genet 92:905-914

Ribaut JM, Jiang C, GonzalezdeLeon D, Edmeades GO, Hoisington DA (1997) Identification of quantitative trait loci under drought conditions in tropical maize, Yield components and markerassisted selection strategies. Theor Appl Genet 94:887-896

Richard C, Osiru DS, Mwala MS, Lubberstedt T (2016) Genetic diversity and heterotic grouping of the core set of southern African and temperate maize (Zea mays L.) Inbred lines using SNP markers. Maydica 61(1):M3

Sabadin PK, de Souza CL, de Souza AP, Garcia AAF (2008) QTL mapping for yield components in a tropical maize population using microsatellite markers. Hereditas 145:194-203

Schnable PS, Ware D, Fulton RS, Stein JC, Wei FS, Pasternak S, Liang CZ, Zhang JW, Fulton L, Graves TA, Minx P, Reily AD, Courtney L, Kruchowski SS, Tomlinson C, Strong C, Delehaunty K, Fronick C, Courtney B, Rock SM, Belter E, Du FY, Kim K, Abbott RM, Cotton M, Levy A, Marchetto P, Ochoa K, Jackson SM, Gillam B, Chen WZ, Yan L, Higginbotham J, Cardenas M, Waligorski J, Applebaum E, Phelps L, Falcone J, Kanchi K, Thane T, Scimone A, Thane N, Henke J, Wang T, Ruppert J, Shah N, Rotter K, Hodges J, Ingenthron E, Cordes M, Kohlberg S, Sgro J, Delgado B, Mead K, Chinwalla A, Leonard S, Crouse K, Collura K, Kudrna D, Currie J, He RF, Angelova A, Rajasekar S, Mueller T, Lomeli R, Scara G, Ko A, Delaney K, Wissotski M, Lopez G, Campos D, Braidotti M, Ashley E, Golser W, Kim H, Lee S, Lin JK, Dujmic Z, Kim W, Talag J, Zuccolo A, Fan C, Sebastian A, Kramer M, Spiegel L, Nascimento L, Zutavern T, Miller B, Ambroise C, Muller S, Spooner W, Narechania A, Ren LY, Wei S, Kumari S, Faga B, Levy MJ, McMahan L, Van Buren P, Vaughn MW, Ying K, Yeh CT, Emrich SJ, Jia Y, Kalyanaraman A, Hsia AP, Barbazuk WB, Baucom RS, Brutnell TP, Carpita NC, Chaparro C, Chia JM, Deragon JM, Estill JC, Fu Y, Jeddeloh JA, Han YJ, Lee H, Li PH, Lisch DR, Liu SZ, Liu ZJ, Nagel DH, McCann MC, SanMiguel P, Myers AM, Nettleton D, Nguyen J, Penning BW, Ponnala L, Schneider KL, Schwartz DC, Sharma A, Soderlund C, Springer NM, Sun Q, Wang H, Waterman M, Westerman R, Wolfgruber TK, Yang LX, Yu Y, Zhang LF, Zhou SG, Zhu Q, Bennetzen JL, Dawe RK, Jiang JM, Jiang N, Presting GG, Wessler SR, Aluru S, Martienssen RA, Clifton SW, McCombie WR, Wing RA, Wilson RK (2009) The B73 maize genome: complexity, diversity, and dynamics. Science 326:1112-1115

Segura V, Vilhjálmsson BJ, Platt A, Korte A, Seren Ü, Long Q, Nordborg M (2012) An efficient multi-locus mixed-model approach for genome-wide association studies in structured populations. Nat Genet 44(7):825-830

Semagn K, bjørnstad $\AA$, Xu Y (2010) The genetic dissection of quantitative traits in crops. Electron J Biotechnol 13:5

Semagn K, Babu R, Hearne S, Olsen M (2014) Single nucleotide polymorphism genotyping using Kompetitive Allele Specific PCR 
(KASP): overview of the technology and its application in crop improvement. Mol Breed 33:1-14

Sharma L, Prasanna BM, Ramesh B (2010) Analysis of phenotypic and microsatellite-based diversity of maize landraces in India, especially from the North East Himalayan region. Genetica 138:619-631

Shehata AI, Al-Ghethar HA, Al-Homaidan AA (2009) Application of simple sequence repeat (SSR) markers for molecular diversity and heterozygosity analysis in maize inbred lines. Saudi J Biol Sci 16:57-62

Sibov ST, De Souza CL, Garcia AAF, Garcia AF, Silva AR, Mangolin CA, Benchimol LL, De Souza AP (2003) Molecular mapping in tropical maize (Zea mays L.) using microsatellite markers. 1. Map construction and localization of loci showing distorted segregation. Hereditas 139:96-106

Sood S, Flint-Garcia S, Willcox MC, Holland JB (2014) Mining natural variation for maize improvement: Selection on phenotypes and genes. In: Tuberosa $\mathrm{R}$ et al (eds) Genomics of plant genetic resources. Springer, Netherlands, pp 615-649

Swarts K, Li H, Romero Navarro JA, An D, Romay MC, Hearne S, Buckler ES (2014) Novel methods to optimize genotypic imputation for low-coverage, next-generation sequence data in crop plants. Plant Genome 7(3). https://doi.org/10.3835/ plantgenome2014.05.0023

Swinnen S, Schaerlaekens K, Pais T, Claesen J, Hubmann G, Yang YD, Demeke M, Foulquie-Moreno MR, Goovaerts A, Souvereyns K, Clement L, Dumortier F, Thevelein JM (2012) Identification of novel causative genes determining the complex trait of high ethanol tolerance in yeast using pooled-segregant whole-genome sequence analysis. Genome Res 22:975-984

Takagi H, Uemura A, Yaegashi H, Tamiru M, Abe A, Mitsuoka C, Utsushi H, Natsume S, Kanzaki H, Matsumura H, Saitoh H, Yoshida K, Cano LM, Kamoun S, Terauchi R (2013) MutMapGap: whole-genome resequencing of mutant F2 progeny bulk combined with de novo assembly of gap regions identifies the rice blast resistance gene Pii. New Phytol 200:276-283

Tamilkumar P, Senthil N, Sureshkumar S, Thangavelu AU, Nagarajan P, Vellaikumar S, Raveendran M (2014) Introgression of low phytic acid locus (lpa2-2) into an elite Maize (Zea mays L.) inbred through marker assisted backcross breeding. Aust J Crop Sci 8:1224-1231

Technow F, Schrag TA, Schipprack W, Bauer E, Simianer H, Melchinger AE (2014) Genome properties and prospects of genomic prediction of hybrid performance in a breeding program of maize. Genetics 197:1343-1355

Thirunavukkarasu N, Hossain F, Arora K, Sharma R, Shiriga K, Mittal S, Mohan S, Namratha PM, Dogga S, Rani TS, Katragadda S, Rathore A, Shah T, Mohapatra T, Gupta HS (2014) Functional mechanisms of drought tolerance in subtropical maize (Zea mays L.) identified using genome-wide association mapping. BMC Genom 15:1182

Thomson MJ (2014) High-throughput SNP genotyping to accelerate crop improvement. Plant Breed Biotechnol 2:195-212

Tian F, Bradbury PJ, Brown PJ, Hung H, Sun Q, Flint-Garcia S, Rocheford TR, McMullen MD, Holland JB, Buckler ES (2011) Genome-wide association study of leaf architecture in the maize nested association mapping population. Nat Genet 43:159-162

Tombuloglu H, Aydin M, Filiz E (2015) Comparative analysis of embryo surrounding region (Esr-6) genes in Turkish maize varieties: sequencing and modeling. Braz J Bot 38:10

Tuberosa R (2012) Phenotyping for drought tolerance of crops in the genomics era. Front Physiol 3:347-382

Tuberosa R, Salvi S (2006) Genomics-based approaches to improve drought tolerance of crops. Trends Plant Sci 11:405-412

Tuberosa R, Salvi S, Sanguineti MC, Landi P, Maccaferri M, Conti S (2002) Mapping QTLs regulating morpho-physiological traits and yield: Case studies, shortcomings and perspectives in drought-stressed maize. Ann Bot (Lond) 89:941-963

Unterseer S, Bauer E, Haberer G, Seidel M, Knaak C, Ouzunova M, Meitinger T, Strom TM, Fries R, Pausch H, Bertani C, Davassi A, Mayer KF, Schön CC (2014) A powerful tool for genome analysis in maize: development and evaluation of the high density $600 \mathrm{k} \mathrm{SNP}$ genotyping array. BMC Genom 15:232-233

Vadez V, Kholova J, Hummel G, Zhokhavets U, Gupta SK, Hash CT (2015) LeasyScan: a novel concept combining 3D imaging and lysimetry for high-throughput phenotyping of traits controlling plant water budget. J Exp Bot 66:5581-5593

Van Inghelandt D, Melchinger AE, Martinant JP, Stich B (2012) Genome-wide association mapping of flowering time and northern corn leaf blight (Setosphaeria turcica) resistance in a vast commercial maize germplasm set. BMC Plant Biol 12:56-71

Vandesompele J, De Preter K, Pattyn F, Poppe B, Van Roy N, De Paepe A, Speleman F (2002) Accurate normalization of real-time quantitative RT-PCR data by geometric averaging of multiple internal control genes. Genom Biol 3:research/0034.11

Veldboom LR, Lee M (1996) Genetic mapping of quantitative trait loci in maize in stress and nonstress environments: I. Grain yield and yield components. Crop Sci 36:1310-1319

Vielle-Calzada JP, de la Vega OM, Hernandez-Guzman G, IbarraLaclette E, Alvarez-Mejia C, Vega-Arreguin JC, JimenezMoraila B, Fernandez-Cortes A, Corona-Armenta G, HerreraEstrella L, Herrera-Estrella A (2009) The palomero genome suggests metal effects on domestication. Science 326:1078-1078

Vinayan MT, Babu R, Jyothsna T, Zaidi PH, Blummel M (2013) A note on potential candidate genomic regions with implications for maize stover fodder quality. Field Crop Res 153:102-106

Wallace JG, Larsson SJ, Buckler ES (2014) Entering the second century of maize quantitative genetics. Heredity 112:30-38

Warburton ML, Xianchun X, Franco J, Melchinger AE, Frisch M, Bohn M, Hoisington D (2002) Genetic characterization of CIMMYT inbred maize lines and open pollinated populations using large scale fingerprinting methods. Crop Sci 42:1832-1840

Wasala SK, Prasanna BM (2012) Microsatellite marker-based diversity and population genetic analysis of selected lowland and midaltitude maize landrace accessions of India. J Plant Biochem Biotechnol 22:392-400

Weber VS, Araus JL, Cairns JE, Sanchez C, Melchinger AE, Orsini E (2012) Prediction of grain yield using reflectance spectra of canopy and leaves in maize plants grown under different water regimes. Field Crops Res 128:82-90

Wen W, Franco J, Chavez-Tovar VH, Yan J, Taba S (2012) Genetic characterization of a core set of a tropical maize race Tuxpeño for further use in maize improvement. PLoS One 7(3):e32626

White WG, Moose SP, Weil CF, McCann MC, Carpita NC, Below FE (2011) Tropical maize: exploiting maize genetic diversity to develop a novel annual crop for lignocellulosic biomass and sugar production. In: Routes to cellulosic ethanol. Springer, New York, pp 167-179

Xu Y, Skinner DJ, Wu H, Palacios-Rojas N, Araus JL, Yan J, Gao S, Warburton ML, Crouch JH (2009) Advances in maize genomics and their value for enhancing genetic gains from breeding. Int $\mathrm{J}$ Plant Genom 2009:957602

Xu J, Yuan YB, Xu YB, Zhang GY, Guo XS, Wu FK, Wang Q, Rong TZ, Pan GT, Cao MJ, Tang QL, Gao SB, Liu YX, Wang J, Lan $\mathrm{H}$, Lu YL (2014) Identification of candidate genes for drought tolerance by whole-genome resequencing in maize. BMC Plant Biol 14:83

Xu C, Ren Y, Jian Y, Guo Z, Zhang Y, Xie C, Fu J, Wang H, Li P (2017) Development of a maize 55 K SNP array with improved genome coverage for molecular breeding. Mol Breed 37:20-32

Yan JB, Kandianis CB, Harjes CE, Bai L, Kim EH, Yang XH, Skinner DJ, Fu ZY, Mitchell S, Li Q, Fernandez MGS, Zaharieva 
M, Babu R, Fu Y, Palacios N, Li JS, DellaPenna D, Brutnell T, Buckler ES, Warburton ML, Rocheford T (2010a) Rare genetic variation at Zea mays crtRB1 increases beta-carotene in maize grain. Nat Genet 42:322-327

Yan JB, Yang XH, Shah T, Sanchez-Villeda H, Li JS, Warburton M, Zhou Y, Crouch JH, Xu YB (2010b) High-throughput SNP genotyping with the Golden Gate assay in maize. Mol Breed 25:441-451

Yang X, Gao S, Xu S, Zhang Z, Prasanna BM, Li L, Li J, Yan J (2010) Characterization of a global germplasm collection and its potential utilization for analysis of complex quantitative traits in maize. Mol Breed 28:511-526

Yang N, Lu YL, Yang XH, Huang J, Zhou Y, Ali F, Wen WW, Liu J, Li JS, Yan JB (2014) Genome wide association studies using a new nonparametric model reveal the genetic architecture of 17 agronomic traits in an enlarged maize association panel. PLoS Genet 10(9):e1004573
Zaidi PH, Rashid Z, Vinayan MT, Almeida GD, Phagna RK, Babu R (2015) QTL mapping of agronomic waterlogging tolerance using recombinant inbred lines derived from tropical maize (Zea mays L) germplasm. PLoS One 10:e0124350

Zaidi PH, Seetharam K, Krishna G, Krishnamurthy L, Gajanan S, Babu R, Zerka R, Vinayan MT, Vivek BS (2016) Genomic regions associated with root traits under drought stress in tropical maize (Zea mays L.). PloS one 11(10):e0164340

Zhang X, Vicente SF, Beyene Y, Semagn K, Crossa J (2014) Genomic selection for tropical maize improvement. In: Proceedings of 12th Asian maize work shop, Bangkok, pp 81-84

Zhang X, Perez-Rodriguez P, Semagn K, Beyene Y, Babu R, LopezCruz MA, San Vicente F, Olsen M, Buckler E, Jannink JL, Prasanna BM, Crossa J (2015) Genomic prediction in biparental tropical maize populations in water-stressed and well-watered environments using low-density and GBS SNPs. Heredity 114:291-299 